\title{
A comparative study of the Co-based amorphous alloy prepared by mechanical alloying and rapid quenching
}

Bogdan Viorel NEAMTUU ${ }^{1, a *}$, Traian Florin MARINCA ${ }^{1, b}$, Horea Florin CHICINAŞ ${ }^{1, c}$, Florin POPA ${ }^{1, d}$, lonel CHICINAŞ ${ }^{1, e}$, Olivier ISNARD ${ }^{2, f}$, Gabriel $\mathrm{ABABEI}^{3,9}$ and Mihai GABOR ${ }^{1, h}$

${ }^{1}$ Materials Science and Engineering Department, Technical University of Cluj-Napoca, 103-105 Muncii Avenue, 400641 Cluj-Napoca, Romania

${ }^{2}$ Université Grenoble Alpes, Institut NEEL, CNRS, 25 rue des martyrs, BP166, F-38042, Grenoble, France

${ }^{3}$ National Institute of Research and Development for Technical Physics, 47 Mangeron Boulevard, 700050 Iasi, Romania

${ }^{4}$ Center for Superconductivity, Spintronics and Surface Science, Technical University of ClujNapoca, Memorandumului Street, No 28, 400114 Cluj-Napoca, Romania

a ${ }^{\star}$ Bogdan.Neamtu@stm.utcluj.ro, ${ }^{\mathrm{b}}$ Traian.Marinca@stm.utcluj.ro, ${ }^{\mathrm{C}} \mathrm{Horea} . C h i c i n a s @ s t m . u t c l u j . r o$, dPopa.Florin@stm.utcluj.ro, ${ }^{\mathrm{e}}$ Ionel.Chicnas@stm.utcluj.ro, ${ }^{\mathrm{f}}$ olivier.isnard@neel.cnrs.fr, ggababei@phys-iasi.ro, 'nihai.gabor@phys.utcluj.ro

Keywords: Amorphous materials, Mechanical alloying, Rapid quenching, Kinetic of crystallization, Magnetic properties

Abstract. Co-Fe-Ni-M-Si-B (M = Zr, Ti) amorphous alloys were prepared via mechanical alloying and rapid quenching. The influence of the preparation conditions over the alloy's characteristics was investigated in the light of several techniques, such as X-ray diffraction, scanning electron microscopy, differential scanning calorimetry, magnetization measurements and in-situ high-temperature X-ray diffraction. It was found that the preparation technique has a significant influence on the thermal stability, magnetic characteristics and the crystallisation kinetic of the amorphous phase. Substitution of transition metals (Ti or Zr) for Si is investigated for the amorphous powders and ribbons. The influence of substitution type over the alloy characteristics is presented and discussed in this paper.

\section{Introduction}

The amorphous materials are widely studied in the last decades due to their potential application as novel materials in various fields. The amorphous soft magnetic materials are characterised by low or even zero magnetocrystalline anisotropy and high electrical resistivity. This characteristic derives from the lack of the long-range atomic order, and imposes them as viable candidates for a series of modern applications.

Among the techniques that were employed to produce amorphous alloys, mechanical alloying and rapid quenching are by far the most used ones [1, 2]. The amorphisation via rapid quenching it is possible if the cooling rates are in the range of $10^{5}-10^{6} \mathrm{~K} / \mathrm{s}$. The amorphisation via mechanical milling, on the other hand, is possible due to the large amount of crystallographic defects (dislocations, grain boundaries, stacking faults, anti-site defects etc.) induced in the powder which destabilizes the crystalline phase [1]. Both techniques have advantages and drawbacks. For example: mechanical alloying can produce amorphous alloys in powder form which is, from the 
applicative viewpoint, very important considering the versatility of the powder technology. On the other hand, the milling time required for powder amorphisation (the milling experiment) is far longer as compared to rapid quenching process. The rapid quenching technique produces amorphous ribbons that are very difficult to be used in order to create magnetic cores with complicated 3D geometry [3]. The alloy contamination risk is reduced in the case of using rapid quenching technique while the contamination with debris from milling bodies must be taken into account when mechanical alloying is used to induce the amorphisation [4]. Moreover, a suitable chemical composition, generally close to deep eutectic composition is needed when the alloy is processed via rapid quenching while the mechanical alloying was proved to induce amorphisation in alloys with chemical composition farther from eutectic compositions [1, 2].

This paper aims to highlight the influence of the processing technique on the crystallisation kinetics and magnetic properties of several Co-based alloys.

\section{Experimental procedure}

In order to prepare the reference alloy $\mathrm{Co}_{70} \mathrm{Fe}_{4} \mathrm{Ni}_{2} \mathrm{Si}_{15} \mathrm{~B}_{9}$ (at. \%) as well as the $\mathrm{Co}_{70} \mathrm{Fe}_{4} \mathrm{Ni}_{2} \mathrm{Si}_{10} \mathrm{~B}_{9} \mathrm{Zr}_{5}$ and $\mathrm{Co}_{70} \mathrm{Fe}_{4} \mathrm{Ni}_{2} \mathrm{Si}_{10} \mathrm{~B}_{9} \mathrm{Ti}_{5}$ (at.\%) alloys, a mixture of elemental powders was prepared. The elemental powders used in this study were: Co (99.8\% purity, particle size range $45-150 \mu \mathrm{m})$, Fe type NC 100.24 (98.5\% purity, particle size < $150 \mu \mathrm{m})$, Ni type 123-carbonyl (99.8\% purity, particle size $<7 \mu \mathrm{m})$, Si $(99.9 \%$ purity, particle size $<150 \mu \mathrm{m}$ ), amorphous B (amorphous powder, 99.8\% purity, particle size $<45 \mu \mathrm{m})$, Ti (99.5\% purity, particle size $<150 \mu \mathrm{m}$ ) and $\mathrm{Zr}$ (99.2\% purity, particle size $<45 \mu \mathrm{m}$ ). The mixtures of elemental powders were subjected to wet mechanical alloying (MA). Benzene was used as process control agent (PCA). $1 \mathrm{ml}$ of $\mathrm{C}_{6} \mathrm{H}_{6}$ was added every time sampling was performed in order to avoid the excessive cold welding phenomena and to counterbalance the PCA evaporation. The samples were milled up to $40 \mathrm{~h}$ in identical conditions using tempered steel balls and vials. The ball to powder ratio (BPR) was chosen to be 16:1 and the rotational speed of the disk was set at $350 \mathrm{rpm}$. Argon atmosphere was used in order to avoid powder oxidation during the milling process.

The amorphous ribbons were prepared by rapid quenching (RQ) from master alloys that were subjected to arc melting in an argon atmosphere. The following parameters were used for the RQ experiments: high purity argon atmosphere, the wheel was manufactured by copper, the crucible was made from quartz, tangential wheel speed was $32 \mathrm{~m} / \mathrm{s}$, the heating and melting of the sample was made by induction, the diameter of the nozzle was $600 \mu \mathrm{m}$ and the disc - crucible distance was $200 \mu \mathrm{m}$. This parameters lead to ribbons of 10-15 mm thickness and 0.9-1 mm width.

The structural characterisation of the powders and ribbons was performed by X-ray diffractions (XRD) using the $\mathrm{Co} \mathrm{K} \alpha$ radiation $(\lambda=1.7903 \AA$ ). An Inel Equinox 3000 diffractometer was used and the scanned interval was $2 \Theta=20-110^{\circ}$. The high-temperature X-ray diffraction (HT-XRD) was performed using the same diffractometer and an Anton-Paar high-temperature chamber (HTK $1200 \mathrm{~N}$ advanced). The XRD patterns were recorded up to the temperature of $900{ }^{\circ} \mathrm{C}$ with a heating rate of $10{ }^{\circ} \mathrm{C} / \mathrm{min}$. One diffraction per minute was the acquisition frequency of the XRD patterns. Preliminary vacuum $\left(10^{-2}\right.$ Torr $)$ was used as the atmosphere inside the high-temperature chamber.

The morphological analysis of the powders and ribbons was performed by scanning electron microscopy (SEM), using a Jeol-JSM 5600 LV electronic microscope. The chemical composition and homogeneity of the samples were analysed using an EDX spectrometer

The differential scanning calorimetry (DSC) was performed with a Setaram Labsys equipment in order to investigate the thermal stability of the amorphous powders and ribbons. The 
investigations were performed in the $20-900{ }^{\circ} \mathrm{C}$ temperature range under Ar with a heating/cooling rate of $20^{\circ} \mathrm{C} / \mathrm{min}$.

The magnetic characteristics of the samples in the amorphous state were investigated by a vibrating sample magnetometer (VSM) by recording their hysteresis loops. A VSM equipment, produced by Lake Shore Cryotronics Inc, was used and the maximum applied field was $800 \mathrm{kA} / \mathrm{m}$.

\section{Results and discussions}

The XRD pattern of the $\mathrm{Co}_{70} \mathrm{Fe}_{4} \mathrm{Ni}_{2} \mathrm{Si}_{15} \mathrm{~B}_{9}$ (at. \%) starting sample (the mixture of elemental powders) and the XRD patters corresponding to the samples obtained by wet milling up to 40 hours are presented in Fig. 1. In the starting sample, the XRD peaks corresponding to elemental $\mathrm{Co}, \mathrm{Si}, \mathrm{Fe}$ and $\mathrm{Ni}$ can be noticed. It worth to be mentioned that in the case of Co, two types of crystallographic structures can be observed: hexagonal Co- hcp (P63/mmc (\#194) space group) and cubic Co - fcc (Fm-3m (\#225) space group). The presence of small quantities of impurities and the crystallographic stresses lead to partial transformation of elemental hcp Co to fcc Co [5, 6]. The Bragg peaks corresponding to $\mathrm{B}$ cannot be noticed in the XRD pattern of the starting sample due to the amorphous state of the used B powder. After 2 hours of milling, the XRD peaks corresponding to $\mathrm{Fe}$ and $\mathrm{Ni}$ are no longer visible and the peaks of Si start to vanish indicating the progressive dissolution of $\mathrm{Fe}, \mathrm{Ni}$ and $\mathrm{Si}$ into Co. After 10 hours of milling, the only Bragg reflexions that are clearly visible correspond to a fcc $\mathrm{Co}$ based solid solution. In the experimentally limits of the XRD technique, we can assume that all the elements are dissolved in Co after 10 hours of milling.

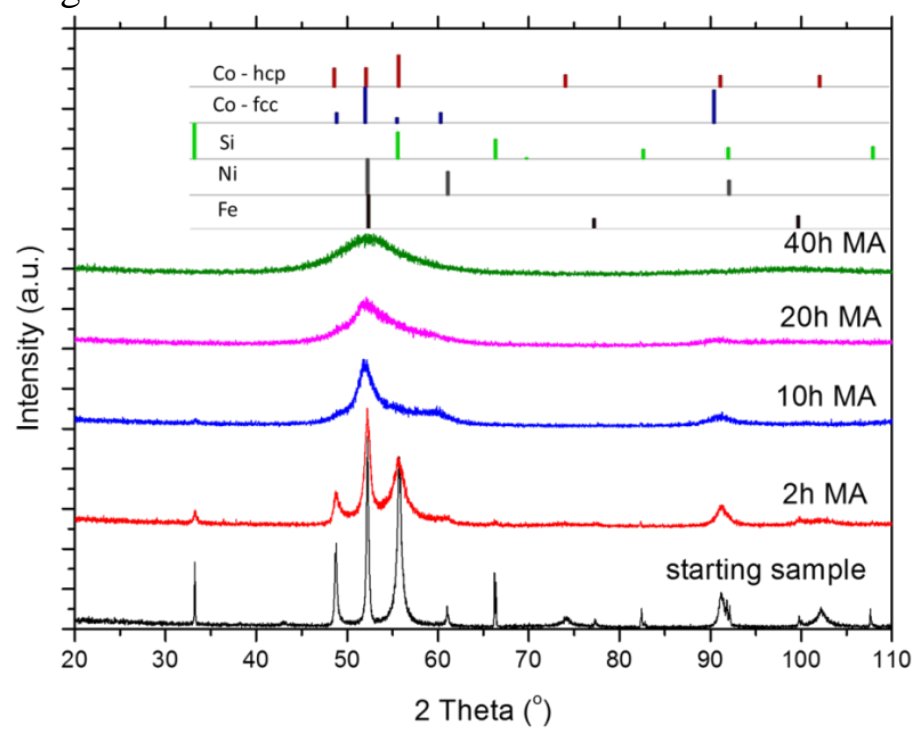

Fig. 1. XRD pattern of the $\mathrm{Co}_{70} \mathrm{Fe}_{4} \mathrm{Ni}_{2} \mathrm{Si}_{15} \mathrm{~B}_{9}$ (at. \%) starting sample and the XRD patters corresponding to the samples obtained by wet milling up to 40 hours.

The XRD pattern of the sample milled up to 25 hours contains a single broad peak situated at the same position in 2 theta as the most intense peak of the fcc Co based solid solution. Even if the peak is very broad and with low intensity, its asymmetric shape (towards higher angles) indicate that the sample contains a mixture of phases. Most probably, after 25 hours of milling, the sample is formed by an amorphous phase that embeds a nanocrystalline fcc Co based solid solution. The XRD pattern of the sample milled up 40 hours contains a single peak that is very broad, with low intensity and with a symmetrical shape. Such an XRD pattern suggests the lack of the long-range 
atomic order indicating the amorphous nature of our sample. In conclusion, we can affirm that 40 hours of wet milling are necessary in order to form the alloy from elemental powders and to induce its amorphisation.

In the case of samples in which 5 at.\% of $\mathrm{Si}$ was substituted with the same amount of $\mathrm{Ti}$ or $\mathrm{Zr}$, the evolution of the structure of the alloy versus milling time is similar to the one above mentioned in the case of $\mathrm{Co}_{70} \mathrm{Fe}_{4} \mathrm{Ni}_{2} \mathrm{Si}_{15} \mathrm{~B}_{9}$ (at. \%) alloy. Due to this reason, it will not be further presented in details. The XRD patterns of the samples wet milled up to 25 hours are presented in Fig. 2. For comparison reasons, the XRD pattern of the $\mathrm{Co}_{70} \mathrm{Fe}_{4} \mathrm{Ni}_{2} \mathrm{Si}_{15} \mathrm{~B}_{9}$ sample wet milled up to 40 hours is given in Fig. 2.

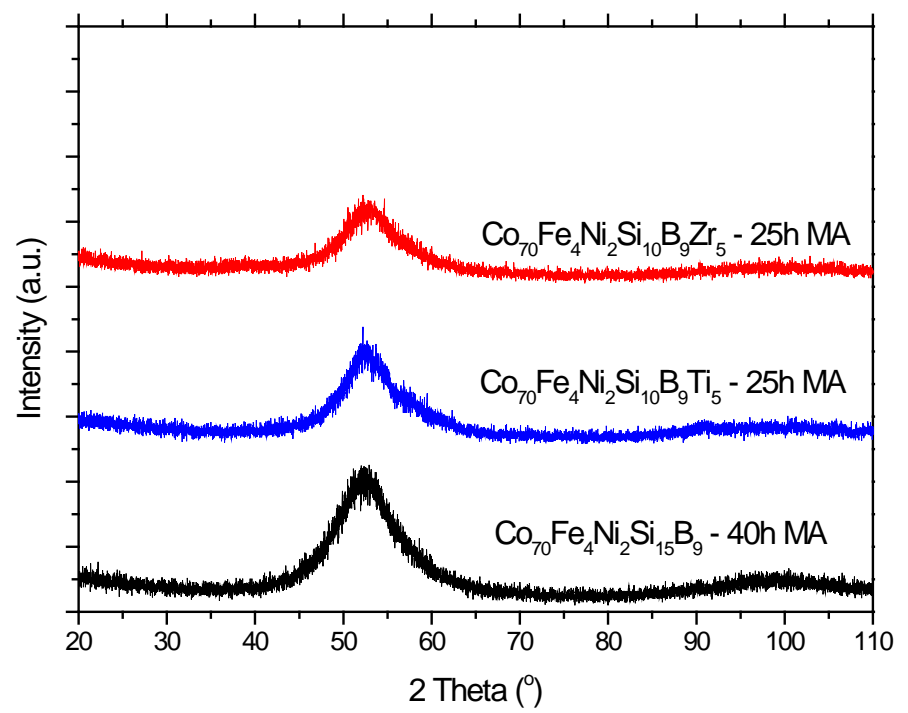

Fig. 2. XRD patterns of the $\mathrm{Co}_{70} \mathrm{Fe}_{4} \mathrm{Ni}_{2} \mathrm{Si}_{15} \mathrm{~B}_{9}$ (at. \%), $\mathrm{Co}_{70} \mathrm{Fe}_{4} \mathrm{Ni}_{2} \mathrm{Si}_{10} \mathrm{~B}_{9} \mathrm{Zr}_{5}$ and $\mathrm{Co}_{70} \mathrm{Fe}_{4} \mathrm{Ni}_{2} \mathrm{Si}_{10} \mathrm{~B}_{9} \mathrm{Ti}_{5}$ (at. \%) alloys obtained after wet milling up to 25 hours

It was noticed that replacing 5 at.\% of Si with 5 at.\% of $\mathrm{Ti}$ or $\mathrm{Zr}$ reduce the milling time needed for the alloy amorphisation. Since the milling parameters were identical with the ones used for the preparation of $\mathrm{Co}_{70} \mathrm{Fe}_{4} \mathrm{Ni}_{2} \mathrm{Si}_{15} \mathrm{~B}_{9}$, we assume that the introduction of the new atomic species (large atoms like $\mathrm{Zr}$ or $\mathrm{Ti}$ ) contribute to the faster structural disordering of the alloy and thus the alloy amorphisation. It is widely accepted that increasing the dissimilarity between atomic sizes of the constituents increase the chances to induce the alloy amorphisation [7].

For comparison reasons, we have prepared amorphous ribbons of the same compositions as the alloys prepared via wet mechanical alloying. The XRD patterns of the ribbons obtained by rapid quenching are presented in Fig. 3. The shape of the XRD patterns of the ribbons demonstrates the amorphous structure obtained after rapid quenching. At the angle of 45.2 degrees in two-theta, a sharp peak can be noticed in all XRD patterns of the amorphous ribbons. This corresponds to the sample holder (incomplete covering of the sample holder with the ribbon) which, in our case, is made of aluminium.

The XRD investigations showed that after 2 hours of milling the powder is not homogeneous. This was also confirmed by the EDX investigations. In the Fig. 4a are presented the distribution maps for the powder wet milled up to 2 hours. It can be observed that $\mathrm{Fe}, \mathrm{Ni}$ and $\mathrm{Si}$ are not uniformly distributed on the analysed surface, their distribution maps presenting areas with higher concentrations. 


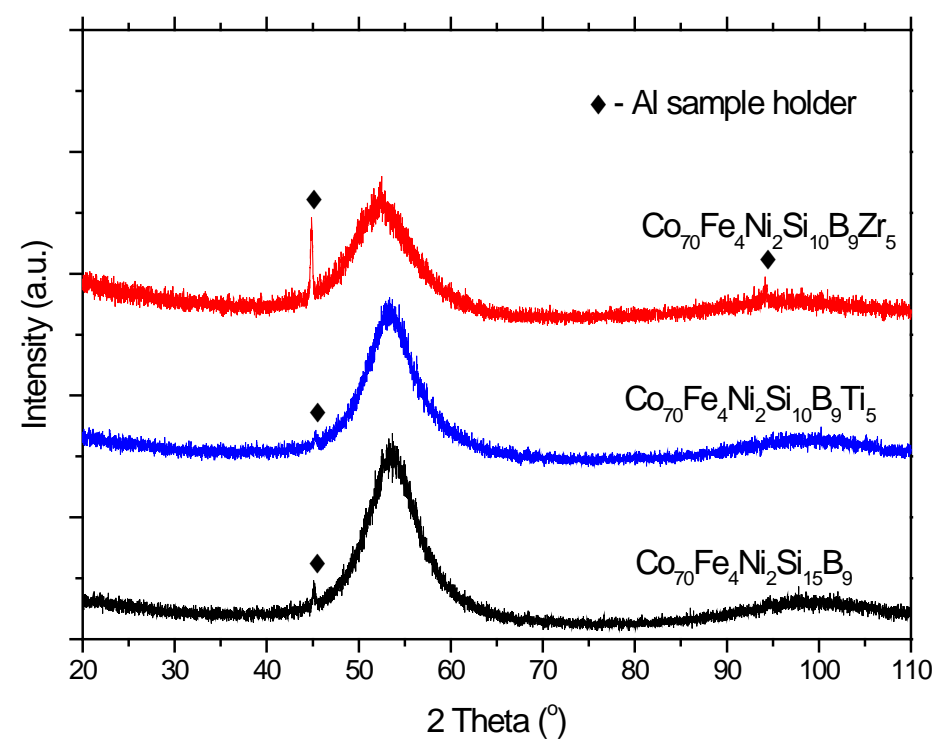

Fig. 3. XRD patterns of the $\mathrm{Co}_{70} \mathrm{Fe}_{4} \mathrm{Ni}_{2} \mathrm{Si}_{15} \mathrm{~B}_{9}$ (at. \%), $\mathrm{Co}_{70} \mathrm{Fe}_{4} \mathrm{Ni}_{2} \mathrm{Si}_{10} \mathrm{~B}_{9} \mathrm{Zr}_{5}$ and $\mathrm{Co}_{70} \mathrm{Fe}_{4} \mathrm{Ni}_{2} \mathrm{Si}_{10} \mathrm{~B}_{9} \mathrm{Ti}_{5}$ (at. \%) amorphous ribbons.

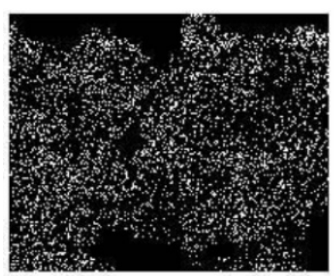

Cobalt Ka1

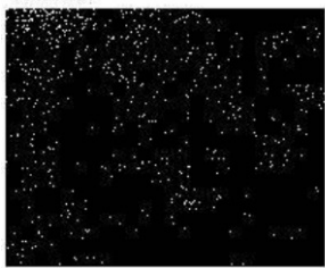

Boron Ka1_2

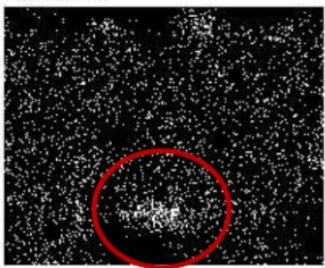

Nickel Ka1

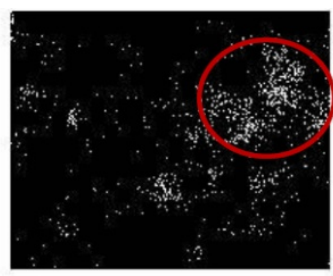

Iron Ka1
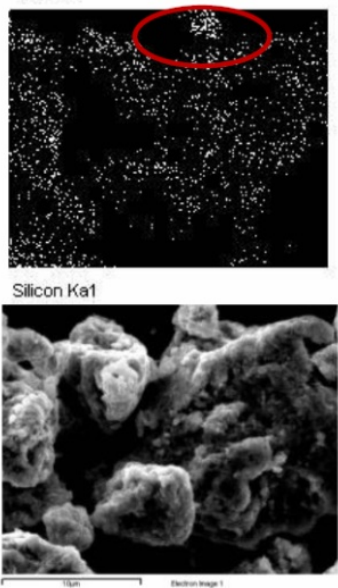

(a)

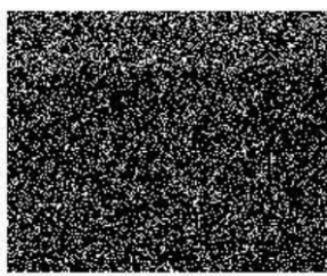

Cobalt Ka1

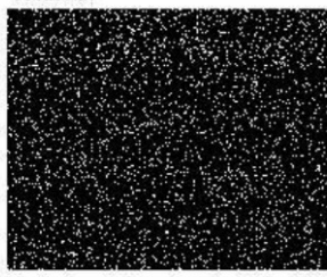

Nickel Ka1

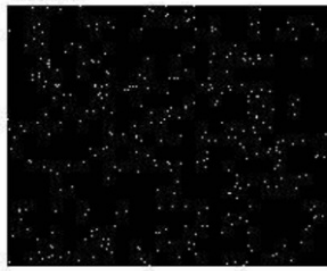

Boron Ka1_2

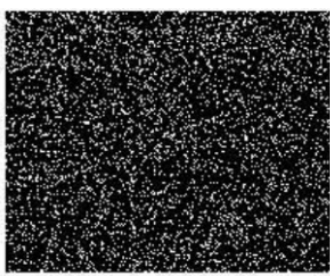

Iron Ka1
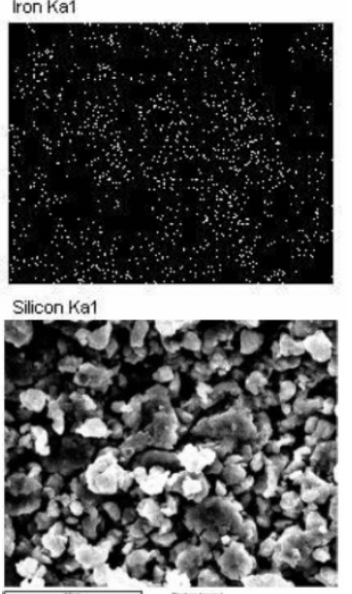

(b)

Fig. 4. EDX analysis of the $\mathrm{Co}_{70} \mathrm{Fe}_{4} \mathrm{Ni}_{2} \mathrm{Si}_{15} \mathrm{~B}_{9}$ sample wet milled up to $2 \mathrm{~h}$ (a) and $40 \mathrm{~h}$ (b).

Increasing the milling time leads to the homogenisation of powder composition and after 40 hours of milling the EDX distribution maps shows a uniform distribution of the Co, Fe, Ni, Si and B in the sample. From the SEM images presented also in Fig. 4, it can be noticed that the particle size decreases upon increasing milling time from 2 hours to 40 hours. According to the literature, wet milling process favours the fracturing phenomena in detriment of cold welding [1]. Also, increasing the milling time leads to cold worked particles with a decreased plasticity favouring 
thus the fragmentation processes. All the above mentioned leads to the decrease of the particles size.

AMORPHOUS POWDERS

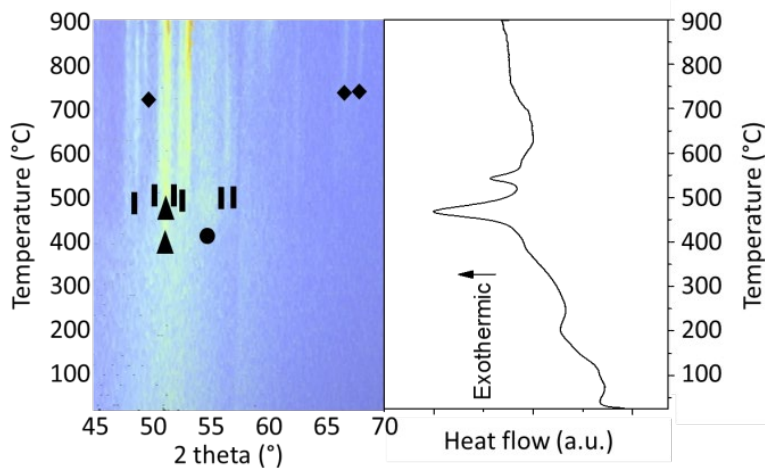

(a)

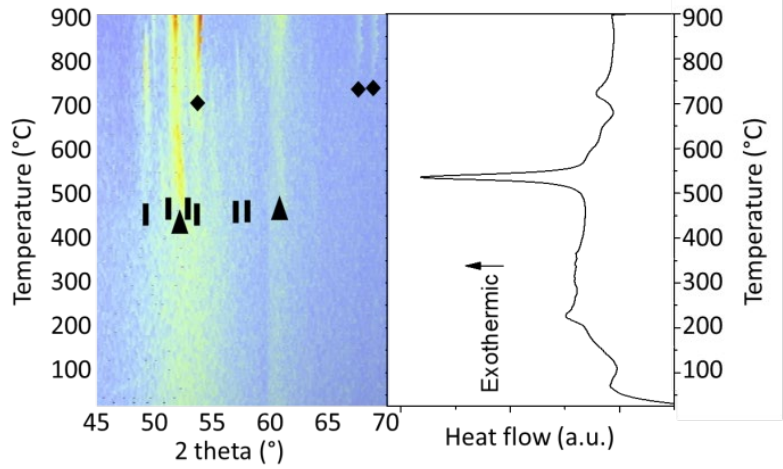

(c)

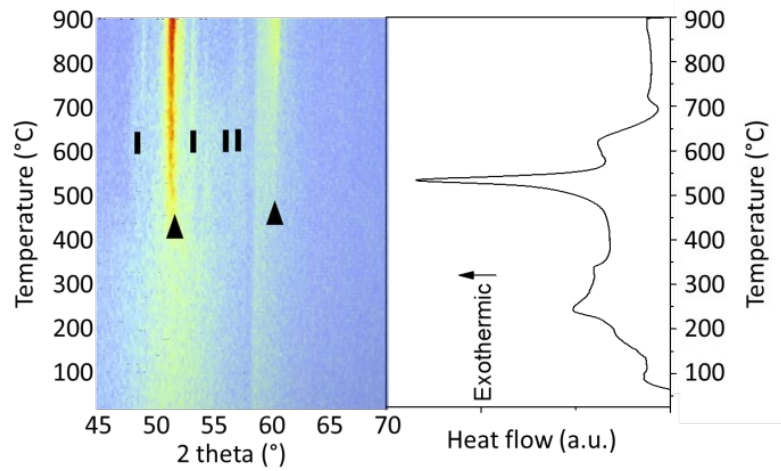

(e)

\section{AMORPHOUS RIBBONS}

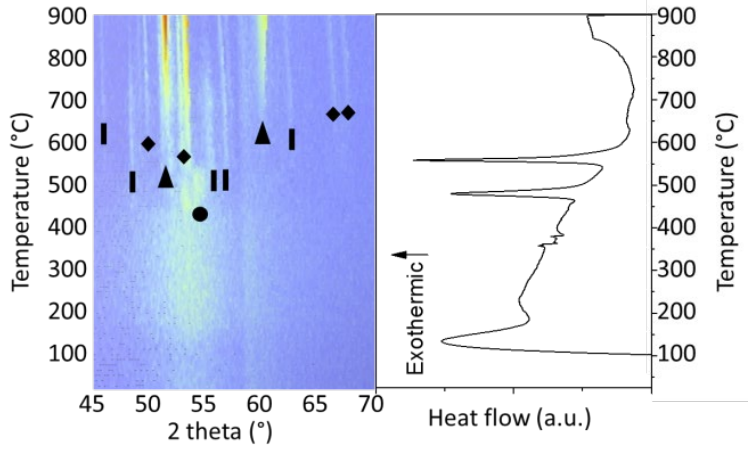

(b)

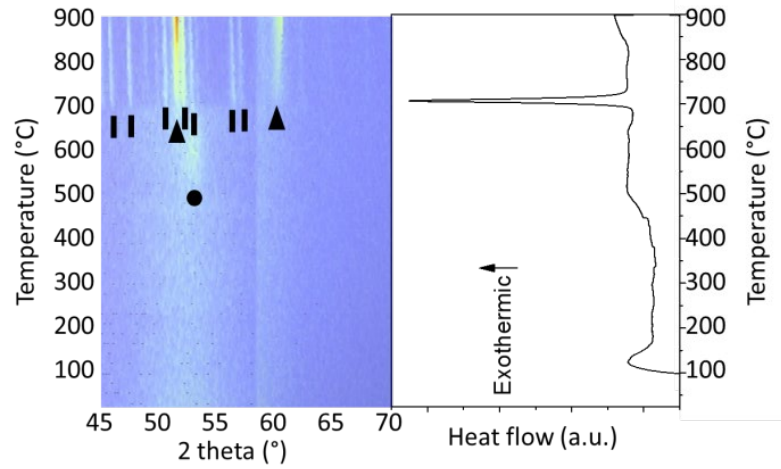

(d)

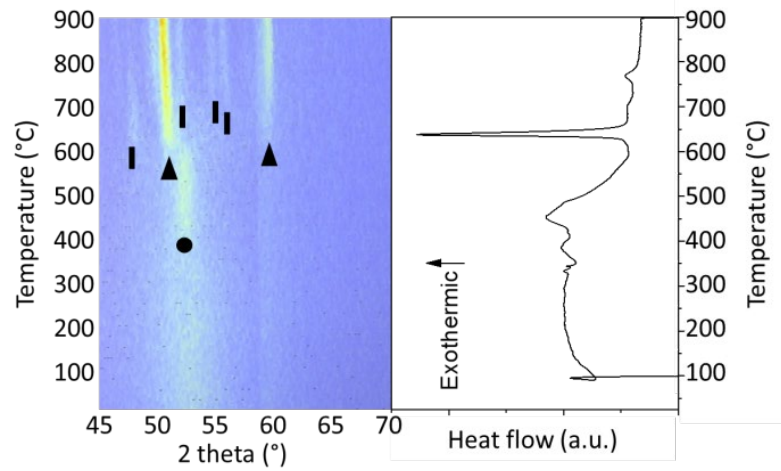

(f)

Fig. 5. Thermal stability of amorphous powders (a, c, e) and ribbons (b, d, f) investigated by HTXRD and DSC. The symbols indicate the positions of the following phases: $\bullet-$ hcp Co based solid solution, $\boldsymbol{\Delta}-$ fcc $\mathrm{Co}$ based solid solution, $-\mathrm{Co}_{2} \mathrm{~B}$ and $-\mathrm{Co}_{2} \mathrm{Si}$. 
The thermal stability and the crystallisation kinetics of the amorphous powders and ribbons were investigated by DSC and HT-XRD. A comparison between amorphous powders and ribbons for each composition is presented in Fig. 5.

It is noticeable that in the case of $\mathrm{Co}_{70} \mathrm{Fe}_{4} \mathrm{Ni}_{2} \mathrm{Si}_{15} \mathrm{~B}_{9}$ powders (Fig. 5a), the amorphous phase is stable up to the temperature of $410{ }^{\circ} \mathrm{C}$. At this temperature, in the HT-XRD plot is visible that the broad peak characteristic of amorphous phase turns into a series of narrower peaks. At the same temperature, in the DSC curve, the onset of a large exothermic reaction can be noticed indicating the primary crystallisation of the amorphous powder. According to the XRD patterns, at this temperature, a mixture of Co - hcp, Co - fcc based solid solutions and $\mathrm{Co}_{2} \mathrm{Si}$ is formed. At higher temperatures, around $530{ }^{\circ} \mathrm{C}$, a new exothermic reaction can be noticed in the DSC curve. According to the HT-XRD analysis, at this temperature, the peaks corresponding to the Co-hcp solid solution disappear. The second exothermic reaction observed on DSC curve was attributed to the allotropic transformation of Co-hcp solid solution. It is known that the pure cobalt presents an allotropic transformation (hcp to fcc) at the temperature of $422{ }^{\circ} \mathrm{C}$. However, in our case, the allotropic transformation occurs at higher temperatures due to the presence of $\mathrm{Si}$ which stabilise the hcp phase according to Co-Si phase diagram [8]. At this temperature $\left(530^{\circ} \mathrm{C}\right)$, the sample consists in a mixture of $\mathrm{Co}$ fcc solid solution and $\mathrm{Co}_{2} \mathrm{Si}$ embedded into an amorphous matrix. At the temperature of $675^{\circ} \mathrm{C}$, the onset of another exothermic reaction is observed in the DSC curve of the $\mathrm{Co}_{70} \mathrm{Fe}_{4} \mathrm{Ni}_{2} \mathrm{Si}_{15} \mathrm{~B}_{9}$ powder. In the HT-XRD plot presented in Fig. 5a, a series of new Bragg reflexions appear. The new Bragg reflexions correspond to the $\mathrm{Co}_{2} \mathrm{~B}$ phase.

The thermal stability of the $\mathrm{Co}_{70} \mathrm{Fe}_{4} \mathrm{Ni}_{2} \mathrm{Si}_{15} \mathrm{~B}_{9}$ amorphous ribbons investigated by DSC and HTXRD is presented in Fig. 5b. It can be observed that the DSC curve of the amorphous ribbon and the DSC curve of the amorphous powder are quite similar. The onset temperature of the two main exothermic reactions noticed on the DSC curve are $465{ }^{\circ} \mathrm{C}$ and $546{ }^{\circ} \mathrm{C}$. The different onset temperatures of the two exothermic reactions as compared to the ones corresponding to the powder can be related to the preparation technique. In our opinion, the amount of stresses induced by mechanical milling is larger as compared to the amount of stresses induced by rapid quenching. In such a case, a lower temperature for the transformations (i.e. crystallisation) should be expected as a result of higher energy stored in the powders as compared to the ribbons. Similar behaviour was reported in the case of amorphous Fe-based alloys prepared by rapid quenching and mechanical alloying. During the first exothermic reaction, the crystallisation of an hcp Co based solid solution occurs according to HT-XRD analysis presented in Fig. 5b. The XRD peaks corresponding to any Co based solid solution cannot be noticed as was observed in the case of amorphous powders. It was previously shown that the formation of the fcc-Co based solid solution is favoured by the presence of large amount of stresses. It is assumed that larger amount of stresses are induced by milling process as compared to rapid quenching. The second exothermic peak corresponds to the allotropic transformation of $\mathrm{Co}$ and the crystallisation of the $\mathrm{Co}_{2} \mathrm{Si}$ phase. At the temperature of $630{ }^{\circ} \mathrm{C}$ the crystallisation of the $\mathrm{Co}_{2} \mathrm{~B}$ phase can be noticed. In conclusion, it can be mentioned that the crystallisation kinetic of the amorphous powder is slightly different as compared to the crystallisation kinetic of the amorphous ribbons.

The investigations concerning the crystallisation of the amorphous $\mathrm{Co}_{70} \mathrm{Fe}_{4} \mathrm{Ni}_{2} \mathrm{Si}_{10} \mathrm{~B}_{9} \mathrm{Zr}_{5} \mathrm{r}$ are presented in Fig. 5c. It can be noticed that the DSC curve present a single large exothermic reaction heaving the onset at the temperature of $480{ }^{\circ} \mathrm{C}$. According to HT-XRD plot, at this temperature, the crystallisation of an fcc-Co based solid solution and $\mathrm{Co}_{2} \mathrm{Si}$ occurs. The higher crystallisation temperature of these amorphous powders as compared to the $\mathrm{Zr}$ free amorphous powders can be explained by the so-called geometrical effects. The random packing of an amorphous material can be increased by the addition of atoms with different atomic radii [9]. 
Naturally, the atomic diffusion in such a structure is slower as compared to the one that occurs in a less dense random packed structure. In this case, the stability of the amorphous structure is enhanced. The occurrence of the hcp Co based solid solution cannot be noticed in the case of $\mathrm{Co}_{70} \mathrm{Fe}_{4} \mathrm{Ni}_{2} \mathrm{Si}_{10} \mathrm{~B}_{9} \mathrm{Zr}_{5}$ powders. This can be explained taking into account at least two factors that promote the formation of fcc Co based solid solution in detriment of hcp-Co based solid solution:

(i) Diminution of the Si content (5 at.\% of Si was replaced with 5 at.\% of $\mathrm{Zr}$ );

(ii) Stresses induced by milling.

At the temperature of $685^{\circ} \mathrm{C}$, the onset of a small exothermic reaction can be noticed. The HTXRD plot revealed that the crystallisation of $\mathrm{Co}_{2} \mathrm{~B}$ phase takes place at this temperature.

The HT-XRD analysis reveals that, in the case of amorphous ribbon of $\mathrm{Co}_{70} \mathrm{Fe}_{4} \mathrm{Ni}_{2} \mathrm{Si}_{10} \mathrm{~B}_{9} \mathrm{Zr}_{5}$, the primary crystallisation leads to the formation of the hcp-Co based solid solution embedded into an amorphous phase. The separation of the hcp phase is difficult to be noticed on the DSC curve but is better visible in the HT-XRD plot as a broad peak on the right side (higher angle) of the amorphous halo. This hcp structure is stable up to the temperature of $692{ }^{\circ} \mathrm{C}$. At this temperature, the transition hcp-Co to fcc-Co occurs and it is accompanied by the formation of the $\mathrm{Co}_{2} \mathrm{Si}$ phase. At the temperature of $692^{\circ} \mathrm{C}$, in the DSC curve, a large exothermic reaction can be noticed.

In the case of $\mathrm{Co}_{70} \mathrm{Fe}_{4} \mathrm{Ni}_{2} \mathrm{Si}_{10} \mathrm{~B}_{9} \mathrm{Ti}_{5}$ amorphous powders, the HT-XRD analysis evidenced that the fcc-Co based solid solution is the main phase that is formed when the powder is heated up to $900{ }^{\circ} \mathrm{C}$. Is worth mentioning that, the hcp-Co based solid solution is not formed in the case of $\mathrm{Co}_{70} \mathrm{Fe}_{4} \mathrm{Ni}_{2} \mathrm{Si}_{10} \mathrm{~B}_{9} \mathrm{Ti}_{5}$ amorphous powders. The reason for this can be the Ti addition and the high level of stresses induced by milling, both favouring the formation of the fcc-Co based structure. According to the Co-Ti phase diagram, Ti stabilises the fcc phase, reducing the temperature range (with about $100{ }^{\circ} \mathrm{C}$ ) in which the hcp structure is stable [8]. A small amount of $\mathrm{Co}_{2} \mathrm{Si}$ was detected by the XRD analysis. However, it seems that the $\mathrm{Ti}$ addition hinder the crystallisation of $\mathrm{Co}_{2} \mathrm{~B}$ phase when the powder is heated up to $900{ }^{\circ} \mathrm{C}$.

Regarding the $\mathrm{Co}_{70} \mathrm{Fe}_{4} \mathrm{Ni}_{2} \mathrm{Si}_{10} \mathrm{~B}_{9} \mathrm{Ti}_{5}$ amorphous ribbon, it can be noticed that its crystallisation is different from that of amorphous powders of the same composition suggesting once again the influence of the preparation technique over the sample characteristics. At the temperature of 435 ${ }^{\circ} \mathrm{C}$, a small exothermic reaction began as can be seen on the DSC curve of this sample. At the same temperature in HT-XRD plot, the crystallisation of the hcp-Co based solid solution is noticed. The hcp structure is stable up to the temperature of $625{ }^{\circ} \mathrm{C}$. At this temperature, takes place the hcp - fcc transition as can be noticed in the HT-XRD plot. Also, at this temperature, a large exothermic reaction can be observed in the DSC plot. At $756{ }^{\circ} \mathrm{C}$, a new set of XRD peaks can be noticed in the HT-XRD plot, indicating the crystallisation of $\mathrm{Co}_{2} \mathrm{Si}$ phase. As in the case of powders, the crystallisation of the $\mathrm{Co}_{2} \mathrm{~B}$ phase cannot be detected.

The influence of the preparation technique and the substitutions on the magnetic characteristics of the amorphous powders and ribbons is presented in Fig. 6. It can be generally noticed that the saturation magnetisation of the amorphous powder is lower than the saturation magnetisation of the amorphous ribbons. Also, the coercive field of the amorphous ribbons is about one-third of the coercive field measured on amorphous powders. The lower saturation magnetisation of the amorphous powders as compared to saturation magnetisation of the ribbons can be explained taking into account several aspects as follow:

(i) The large number of structural defects and high level of stresses induced by milling [1];

(ii) The presence of a certain amount of superparamagnetic particles. Wet milling route promotes the fracturing phenomena leading to the decrease of the particles size. For long milling duration, the occurrence of particles with superparamagnetic behaviour is plausible [10]. 
(iii) Powder contamination. It was previously proved that during wet milling the powder contamination takes place in two ways as follows: (1) surface contamination - the PCA is adsorbed on the particles surface; (2) chemical composition alteration - atoms resulted from the decomposition of the PCA are incorporated into alloy during milling $[4,11]$. The above mentioned will lead to a decreased magnetic moment per unit mass and thus a decreased saturation magnetisation

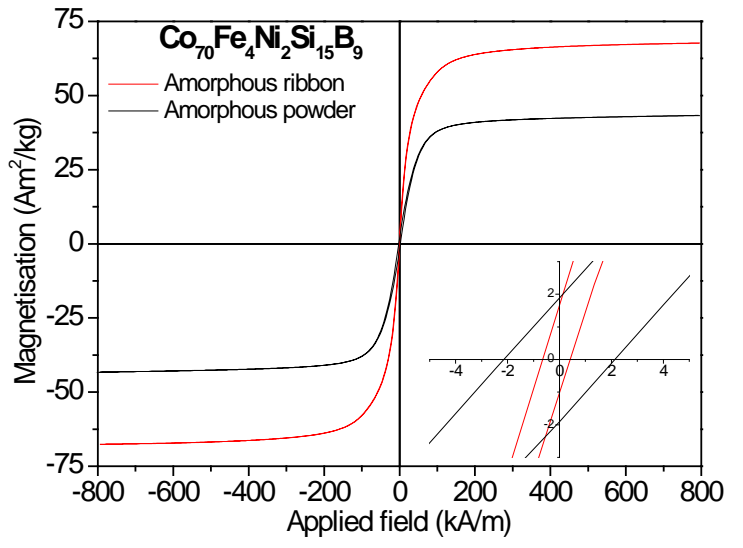

(a)

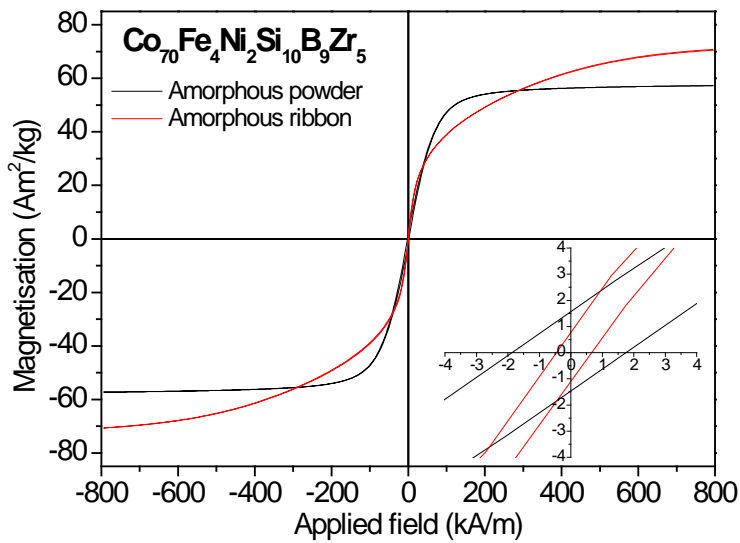

(b)

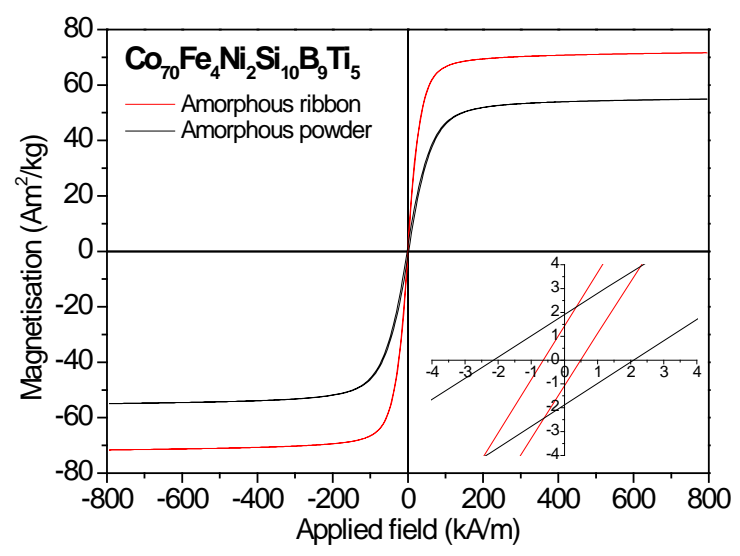

(c)

Fig. 6. Hysteresis loops corresponding $\mathrm{Co}_{70} \mathrm{Fe}_{4} \mathrm{Ni}_{2} \mathrm{Si}_{15} \mathrm{~B}_{9}$ (at. \%), $\mathrm{Co}_{70} \mathrm{Fe}_{4} \mathrm{Ni}_{2} \mathrm{Si}_{10} \mathrm{~B}_{9} \mathrm{Zr}_{5}$ and $\mathrm{Co}_{70} \mathrm{Fe}_{4} \mathrm{Ni}_{2} \mathrm{Si}_{10} \mathrm{~B}_{9} \mathrm{Ti}_{5}$ (at. \%) amorphous powders (black curves) and ribbons (red curves). The $0 x$ axis in the insets of each graph (6a, $6 \mathrm{~b}$ and $6 \mathrm{c})$ is in $\mathrm{kA} / \mathrm{m}$.

According to the literature, larger coercive field is expected for powders as compared to amorphous ribbons due to the increased number of domain wall pining centres. Mechanical alloying route induces a larger amount of free volume content as compared to rapid quenching [12]. Also, it was above mentioned that mechanical alloying leads to samples with a large number of structural defects and high level of stresses as compared to rapid quenching that naturally increases the coercivity.

\section{Summary}

Co-Fe-Ni-M-Si-B (M = Zr, Ti) amorphous alloys were successfully prepared via wet mechanical alloying and rapid quenching. The alloy $\mathrm{Co}_{70} \mathrm{Fe}_{4} \mathrm{Ni}_{2} \mathrm{Si}_{15} \mathrm{~B}_{9}$ is obtained in an amorphous state after 40 hours of wet mechanical alloying. Substitution of Si with $\mathrm{Zr}$ or Ti leads to a significant 
reduction of the milling duration for the alloy amorphisation. It was shown that the alloys prepared in powder form via mechanical alloying crystallise at a lower temperature as compared to their counterpart in form of amorphous ribbons. Substitution of $\mathrm{Si}$ with $\mathrm{Zr}$ or Ti leads to increased thermal stability of the amorphous phase. Also, it was evidenced by HT-XRD and DSC measurements that the preparation technique and the substitution made ( $\mathrm{Si}$ for $\mathrm{Zr}$ or $\mathrm{Si}$ for $\mathrm{Ti}$ ) modifies the crystallisation kinetic of the alloys. Magnetic measurements revealed that the saturation magnetisation of the amorphous powder is lower than the saturation magnetisation of the amorphous ribbons. Also, it was noticed that the coercive field of the amorphous ribbons is about one third of the coercive field measured on amorphous powders and was explained based on the particularities of the wet mechanical alloying process.

\section{Acknowledgements}

This work was supported by a Grant of the Romanian National Authority for Scientific Research CNCS - UEFISCDI, Project number PN II-RU-TE-2012-3-0367.

\section{References}

[1] C. Suryanarayana, Mechanical alloying and milling, Prog. Mater. Sci., 46 (2001), 1-184. https://doi.org/10.1016/S0079-6425(99)00010-9

[2] C. Suryanarayana, A. Inoue, Bulk Metallic Glasses, CRC Press, Boca Raton, London, New York, 2010.

[3] C. Suryanarayana, A. Inoue, Iron-based bulk metallic glasses, Int. Mater. Rev., 58 (2013) 131-166. https://doi.org/10.1179/1743280412Y.0000000007

[4] B.V. Neamţu, H.F. Chicinaş, T.F. Marinca, O. Isnard, O. Pană, I. Chicinaş, Amorphisation of Fe-based alloy via wet mechanical alloying assisted by PCA decomposition, Mater. Chem. Phys., 183 (2016) 83-92. https://doi.org/10.1016/j.matchemphys.2016.08.005

[5] J. Y. Huang, Y. K. Wu and H. Q. Ye, Allotropic transformation of cobalt induced by ball milling, Acta Mater. 44 (1996) 1201 - 1209. https://doi.org/10.1016/1359-6454(95)00234-0

[6] O. S. Edwards, H. Lipson, Imperfections in the structure of cobalt. I. Experimental work and proposed structure, Proc. Royal Soc. A, $180 \quad$ (1942) 268 - 277. https://doi.org/10.1098/rspa.1942.0039

[7] A. Inoue, Stabilization of metallic supercooled liquid and bulk amorphous alloys, Acta Mater. 48 (2000) 279-306. https://doi.org/10.1016/S1359-6454(99)00300-6

[8] Hiroaki Okamoto, Mark E. Schlesinger, ASM Handbook Vol. 3, Alloy Phase Diagrams, Ohio, 2016.

[9] B.V. Neamţu, H.F. Chicinaş, T.F. Marinca, O. Isnard, I. Chicinaş, Preparation and characterisation of $\mathrm{Co}-\mathrm{Fe}-\mathrm{Ni}-\mathrm{M}-\mathrm{Si}-\mathrm{B}(\mathrm{M}=\mathrm{Zr}, \mathrm{Ti})$ amorphous powders by wet mechanical alloying, J. Alloy Compd., 673 (2016) 80-85. https://doi.org/10.1016/j.jallcom.2016.02.233

[10] J.Y. Yang, J.S. Wu, T.J. Zhang, K. Cui, Multicomponent mechanical alloying of $\mathrm{Fe}-\mathrm{Cu}-\mathrm{Nb}-$ Si-B, J. Alloy. Compd. 265 (1998) 269-272. https://doi.org/10.1016/S0925-8388(97)00308-3

[11] B.V. Neamţu, O. Isnard, I. Chicinaş, C. Vagner, N. Jumate, P. Plaindoux, Influence of benzene on the $\mathrm{Ni}_{3} \mathrm{Fe}$ nanocrystalline compound formation by wet mechanical alloying: An investigation combining DSC, X-ray diffraction, mass and IR spectrometries, Mater. Chem. Phys., 125 (2011) 364-369. https://doi.org/10.1016/j.matchemphys.2010.10.056

[12] A.H. Taghvaei, M. Stoica, K.G. Prashanth, J. Eckert, Fabrication and characterization of bulk glassy Co40Fe22Ta8B30 alloy with high thermal stability and excellent soft magnetic properties, Acta Mater. 61 (2013) 6609-6621. https://doi.org/10.1016/j.actamat.2013.07.045 